\title{
Occurrence of post-endodontic pain after single-visit RCT using Balanced Force technique and two reciprocating system when apical patency is maintained.
}

\author{
Dr. Jorge Paredes Vieyra, Fabian Ocampo Acosta, Francisco Javier Jiménez Enriquez, Rosendo \\ Andres Rojas Alvarado \\ D.D.S., MSc, PhD \\ 710E San Ysidro Blvd. suite "A" \#1513 San Ysidro California 92173 USA \\ D.D.S., MSc Histopathology Department \\ D.D.S., MSc, PhD Oral Surgery \\ MD., MPh. Epidemiology department \\ Universidad Autónoma de Baja California, México
}

\begin{abstract}
Aim. The goal of this research was to relate the occurrence of post-endodontic pain after single-visit RCT using Balanced Force technique and two reciprocating system when AP is conserved.

Methodology: Two hundred and sixteen of 245 patients aged 18-65 years were incorporated in this research. All patients had teeth selected for conventional RCT for prosthetic reasons detected with only vital pulps. For hand instrumentation, Balanced Force were used. All canals were clean and shaped with hand Flex-R files. For mechanical shaping, all instruments were prepared with Protaper Next and Reciproc instruments in continuous brushing and reciprocating mode respectively. Final irrigation with cold $\left(8^{\circ} \mathrm{C}\right) 17 \%$ EDTA served as a lubricant.

Results: The average age of the 216 participants registered in this research was 54 years. No statistically significant difference $(\mathrm{p}>.05)$ among the groups were found regarding degree or duration of pain. There was no statistically significant difference ( $p>$.05) among the Balanced Force technique, PTN and R techniques in relation to the occurrence of post/endodontic ache at any of the three time points measured (Table 3, 4).

Conclusions. The incidence of post-endodontic pain is lower when AP is maintained and presence/absence of pre-operative pain has to be consider. When previous symptoms are present, occurrence and period of pain is longer in teeth with this condition that when AP is maintained. It can be established that conserving AP with a thin K-file can help to prevent post-endodontic pain in some specific cases.
\end{abstract}

Keywords. Flare ups, post-operative pain, post-endodontic pain, pain, apical healing

\section{Introduction}

Post-endodontic pain is an ache after root canal treatment (RCT) and is described by more than $35 \%$ of patients regardless of periapical condition. Management of it is essential in endodontic practice (1).

Pain of endodontic origin is widely feared by the patients, accurate information of pain occurrence and strictness related with pulpal or periradicular illness and its decrease by RCT has the possibility to change the attitudes of the patients, general dentists, endodontists and other health care professionals (2).

Debris, organic tissue, microbes, and irrigants solutions can be sent beyond the apex through RCT, and can lead to post-operative problems, such as intensive pain or flare-ups. Therefore, acceptable care of the working length (WL) may diminish the expulsion of remains through the apical foramen (AF) but may not avoid this entirely (3). 
Accumulation of soft material remnant in the apex is a usual occurrence that can produce obstruction of root canal (RC). This condition can be prevented if patency of the AF is maintained (4). Presently, maintaining apical patency (AP) is suggested thru RCT (5).

Apical patency is the action of use a tiny hand file to maintain the apical constriction (AC) open. it is a method that keep the apex free of remains (6). A patency instrument is described as a tiny bendable K-file, which is used through the AC $(7,8)$. The instruments employed to gain AP are often the same instruments primarily used to negotiate RC (9).

To improve clean and shape the canal, has been proposed technique like the concept of balanced forces (10). The benefits of Balanced forces (BF) are that it reduces the chance of change of WL, decrease canal alterations and formation of apical ledges (5), permits maintenance of the integrity of the AC (11), and increase the palpable appreciation of the professional through RCT (8).

Main improvements in mechanical shaping and metallic properties have led to the improve of plentiful methods with novel designs in modern years. However, all methods and tools existing to this time are related with some level of expulsion of remains $(12,13)$.

The model of one-file for canal shaping was presented in endodontics (14) with the promotion of Reciprocal (VDW, Munich, Germany) and WaveOne (Dentsply Tulsa, Johnson City, TN) techniques. These metallic tools are made-up with a Ni-Ti alloy named M-Wire by means of a novel thermal management procedure (15). The watch-winding motion comprises an initial turning of the device in an anticlockwise way, during which the file enters and cuts the dentin, after that a sequence in clockwise way, meanwhile the file is liberated.

All root canal preparation techniques cause apical extrusion to some degree; however, the amount of extrusion may vary (16-17). Some other factors may disturb the occurrence of post-endodontic pain when AP was conserved in concordance to when it was not (18).

One of the unproven details for not operating AP is the probable passage of remains throughout the AF, a clinical situation associated with post-endodontic pain $(12,19)$.

Some other authors indicated that maintaining AP would not produce more post- operative complications, requiring it is reasonably made (18).

The goal of this research was to relate the occurrence of post-endodontic pain after single-visit RCT using Balanced Force technique and two reciprocating system when AP is conserved.

\section{Materials and Methods}

This clinical research took place at the University Autonomous of Baja California, School of Dentistry, Tijuana, Mexico. The subjects review committee accepted the research, and conducted in accordance with ethical principles (including the World Medical Association Declaration of Helsinki).

Three certified endodontists trained in the procedures, devices, and systems investigated took part in the research. All experts tracked a pre-established procedure for the Balanced Force technique, ProTaper Next, and Reciproc instrument systems.

The principal inclusion parameters were absence of radiographic sign of apical periodontitis and a diagnosis of irreversible pulpitis (IP) established by affirmative response to hot and cold examinations.

Thermal pulp examination was achieved by the corresponding author, and radiographic analysis was established by 3 certified endodontists. Clinical requirements were established on the next conditions: 1) The purposes and necessities of the research were spontaneously accepted. 2) Clinical Management was pointed to patients in physical and mental well-being. 3) All teeth had vital pulps and absence of apical periodontitis. 4) Positive thermal stimulation with EndoIce (Hygenic Corp, Akron, OH). 5) Teeth with enough coronal structure for rubber dam isolation. 6) No RCT done before the research. 7) No painkillers or antibiotics used 7 days' prior the clinical events started.

Exclusion parameters were the necessity for retreatment, gravidity, impossibility to obtain patient's approval, patients who didn't complete inclusion necessities, a history of medication for chronic pain or those compromising the immune response, patients younger than 18 years and the existence of mishaps or difficulties during RCT (calcified canals, impracticality of achieving AP in any canal).

The subsequent records were collected in clinical archives. The judgment of vital tissue was established by accumulating dental record and doing digital radiography, periodontal assessment, percussion, and cold test. 
The diagnostic results were evaluated by relating the tooth's reaction versus a contiguous tooth with the same vital condition.

This condition was rechecked by the presence of bleeding thru the access. If the thermal test was positive and there was bleeding during endodontic access, the tooth was established as vital. The occurrence or nonexistence of pre-operative pain (yes/no) was noticed. We requested the patients whether they had pain or discomfort 7 days previously the event. Teeth (posterior/anterior) and location (superior/inferior) were also added.

\section{Patient selection}

Two hundred and sixteen of 245 patients (119 women and 97 men) aged 18-65 years were incorporated in this research (Fig. 1). Sample size estimate was achieved according with a method for this specific purpose (Cochran's method, 1986). Therefore, the 72 teeth allocated to each group were adequate to confirm an essential sample.

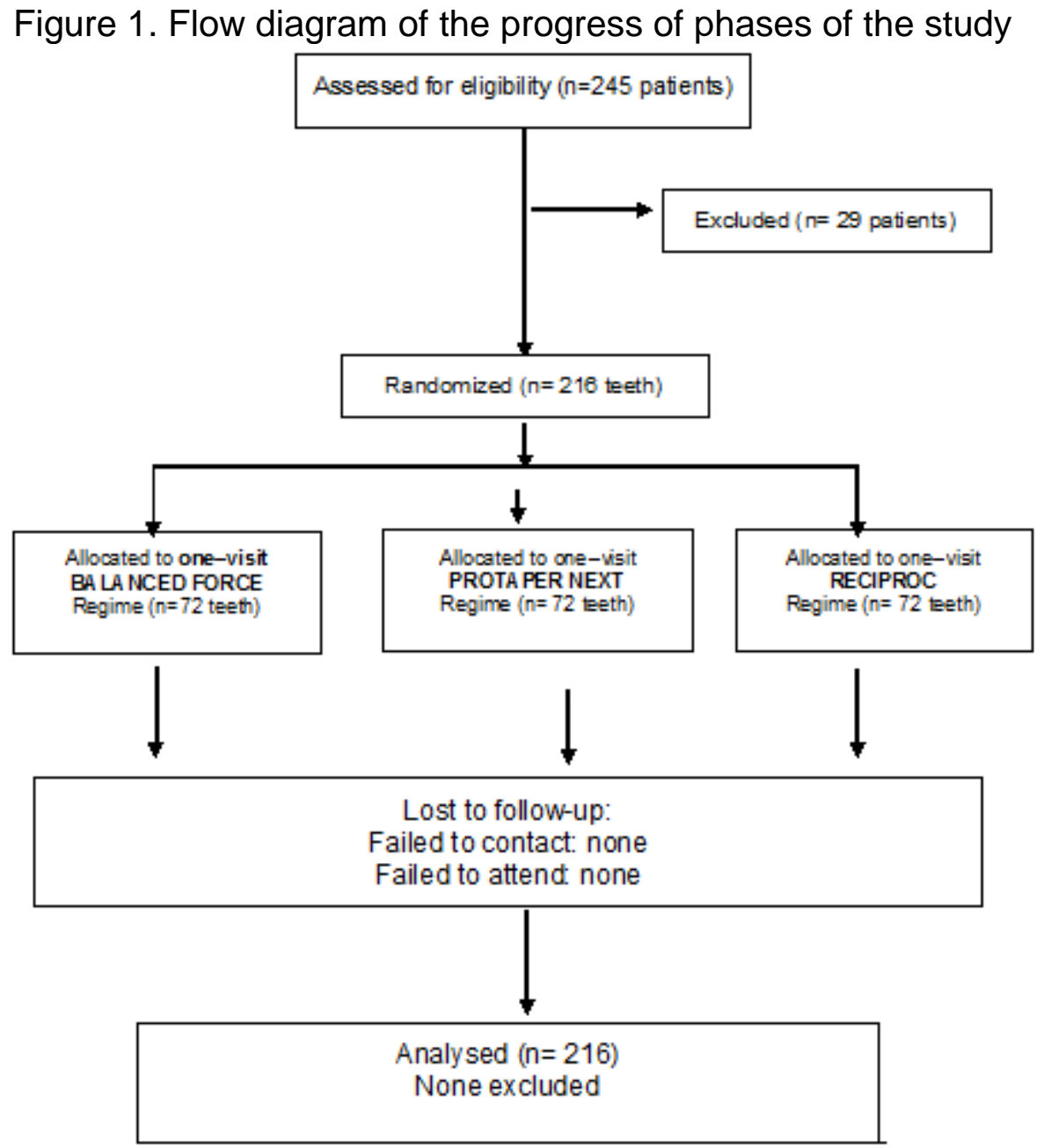

All patients had upper or lower molar, premolar or anterior teeth selected for conventional RCT for prosthetic reasons detected with vital pulps. Clinical cases with non-vital teeth and apical periodontitis, endodontic retreatment, root resorption, undeveloped apex, or a root canal with severe curvature $\left(>35^{\circ}\right)$ or a radiographically untraceable canal path were all rejected from the study (as mentioned above).

Patients rejecting to join the research, those with issues with single-visit RCT, those consuming a specific kind of medicine such as painkillers or NSAIDs, and participants with some unrestrained systemic ailment were excluded too.

All participants were knowledgeable of the goals, risks and strategy of the study, and written permissions were gained previously their addition.

Random Selection of instrumentation groups.

Of the sample of 216 teeth, 72 were selected to the 3 instrumentation methods. The study strategy included 3 experts, each expert prepared 72 teeth, 24 per technique. 


\section{Treatment Protocol}

All patients were anesthetized with two carpules of articaine 2\% with epinephrine 1:200,000 (Septodont, Saint-Maur des-Fosses, France) was administered. In cases in which supplemental anesthesia was needed, intraligamental articaine $2 \%$ was injected. After absolute isolation, the tooth was sanitized with $5.25 \%$ $\mathrm{NaOCl}$.

Cavity access was performed by using \# 331 bur (Dentsply International, York, PA), with high-speed and water cooling during the procedure. $5.25 \% \mathrm{NaOCl}$ were used to clean the coronal cavity. The canals were evaluated with \#10 K-type hand files (Flex-R files, Moyco/Union Broach, York PA, USA).

The standard method involved the following steps: Access was gotten, REDTA (Roth International, Chicago, IL) lubricant was located at the entry of the canals. Determination of WL was first determined with a \#15 k-file and the Root ZX electronic device (J Morita, Irvine CA, USA), following by subtracting $0.5 \mathrm{~mm}$ from the measurement, which was calculated with the assistance of a metallic ruler. with digital radiographic confirmation (Schick Technologies, NY, USA). A glide path to the WL was then established.

Pulpal cavity was dried with a sterilized cotton pellet. Lubricant was positioned at the entry of canals (ie, measurements were made along humid canals). A \#15 file attached to Root ZX apex locator was used to calculate WL. WL was calculated with \#20 and \#25 files respectively. If there was no arrangement among measures gotten by using the 3 files, the data that was dissimilar was reevaluated. If discrepancy continued, the measure conveyed with the thicker file was designated. WL was confirmed with a digital radiograph. In the event of dissimilarity between radiographic and electronic quantities, the last was designated. For hand instrumentation, Balanced Force were used. All canals were clean and shaped with hand Flex-R files (fMoyco/Union Broach, York PA, USA). Gates-Glidden burs (Dentsply Maillefer) sizes \#2 and \#3 were used at the entry of the canals. For mechanical shaping, all instruments were used with a micro motor (VDW Silver Reciproc Motor). Torque and rotation were established independently for each instrument method used. Protaper Next and Reciproc instruments were used in continuous brushing rotary motion and reciprocating mode respectively.

Dentinal remains were eliminated from the file by means of a gauze, instantaneously to the next instrument change (ProTaper Next system) or after 2-3 in-and-out (pecking) movements (Reciproc systems) allowing to the manufacturer's commendations. Each root canal was irrigated with $2.5 \mathrm{~mL} 2.6 \% \mathrm{NaOCl}$. Irrigation was achieved using a 24-G needle (Max-I-Probe; Tulsa Dental, York, PA) through access and a 31-G NaviTip needle (Ultradent Products Inc, South Jordan, UT) when getting the WL after each instrument insertion.

Group BF. For the Balanced force group, the root canals were cleaned and shaped using a \#40 instrument for thin or curved canals and a \#55 file for widespread canals.

Group PTN. For the Pro Taper Next group, Sx files, X1 and X2 (ProTaper Universal system; Dentsply, Ballaigues, Switzerland) were used for preflare and preparation of thin and curved canals and X3 and X4 (40/.06) for preparation of wide canals up to the WL. The instruments were operated using a continuous rotary brushing motion at a speed of $300 \mathrm{rpm}$ and a torque of $2 \mathrm{Ncm}$.

Group R. R25 (25/.08) instrument was used in thin and curved RC, and R40 files (40/.06) were used in wide canals. Three in-and-out motions were used with lengths not beyond $3 \mathrm{~mm}$ in the three thirds of the canal until reaching the estimated WL.

Hand and rotary files were employed in just 1 tooth (single use) and then excluded. AP was conserved through all the procedures used by using a \#10 K-type file at WL.

After instrumentation phase, pulp chamber was rinsed with $1 \mathrm{~mL} 2.6 \% \mathrm{NaOCl}$, agitated ultrasonically. Ultrasonic activation was performed using an Irrisafe ultrasonic 20.00 tip (Satelec, M erignac, France) at $50 \%$ power of the MiniEndo ultrasonic unit (Kerr Endo) to place the tip $3 \mathrm{~mm}$ from the WL for 30 seconds per canal. Then, each experimental group received a final irrigation with cold $\left(6^{\circ} \mathrm{C}\right) 17 \%$ EDTA gently delivered to the WL using a cold $\left(6^{\circ} \mathrm{C}\right)$ sterile metallic micro cannula attached to the Endovac negative pressure irrigation system (Kerr Endo) for three minutes to eliminate the smear layer and reduce postendodontic pain. Caution was taken to ensure that the micro cannula would suction correctly by detecting the system's transparent evacuation tube. In case there was any obstruction, the micro cannula was instantly substituted.

Repeat of WL was established again by using EAL as describe before using \#35, \#40 and \# 45 files.

The root canals were then desiccated with disinfected paper cones and filled at the same visit. Gutta-percha cones (Dentsply Maillefer) were laterally compacted with \#20 nickel-titanium spreaders (Dentsply 
Maillefer) and AH-plus sealer (Dentsply Maillefer). Entrance openings of anterior teeth were etched and repaired with Fuji IX (GC Corp, Tokyo, Japan). For posterior teeth, a rebuilding was placed with the same method.

Assessment of Post-endodontic pain and Statistical Analysis

Patients were informed of the probable incidence of pain for days following RCT and received a survey form to be finished and returned three days after. In it, they proof the occurrence or nonappearance of postendodontic pain, its period and level of distress rated as follows: mild pain: any discomfort of any duration that does not require treatment; moderate pain: pain that requires and is relieved with analgesics; and severe pain: any pain that is not calmed with treatment (analgesics).

Two hundred and ten of the 216 surveys were returned correctly responded and in the date requested. Of these, 69 belonged to BF group, 70 to PTN group and 71 to R group. Rest of the 216 were received one day after and were included in the data analysis.

Outcomes of groups BF, PTN and R associated to occurrence (yes/no), level (mild, moderate, severe), and interval (days) of post-endodontic ache were evaluated, focusing to diagnostic factors: condition of tooth (all vital), occurrence or nonappearance of pre-operative pain, group of teeth (molar/premolar or anterior), or location (Maxillary, Mandibular).

Outcomes were examined with the Chi-Square test for the occurrence of post-endodontic pain.

\section{Results}

The clinical structure of the participants is shown in Table 1. The average age of the 216 participants registered in this research was 54 years. No statistically significant difference $(p>.05)$ among the groups were found regarding degree or duration of pain. The post-endodontic pain marks were seen 24 hours later in the three groups with an important decline subsequently.

No statistically important difference was seen between the 3 groups evaluated in the research in terms of level and amount of analgesic medicine consumption ( $\mathrm{p}>.05$, Table 2-3). In general, analgesic consumption was limited to the next 24 hours after RCT in all the groups evaluated. Nobody of the 216 patients stated acute pain or flare-ups during the phase of the research (Table 3). In situations with informed occurrence of pre-operative pain, periods of post-endodontic pain were considerably more. There was no statistically significant difference ( $>>$.05) among the Balanced Force technique, PTN and R techniques in relation to the occurrence of post/endodontic ache at any of the three time points measured (Table 2, 3).

\section{Group of Teeth}

No statistically significant differences were encountered between groups about occurrence, grade, or length of post-endodontic pain among anterior and posterior teeth.

\section{Post-endodontic pain associated to the arch}

In maxillary teeth, differences among groups were not statistically relevant concerning occurrence, level, or length of post-endodontic pain.

In mandibular teeth, post-endodontic pain was significantly lengthier ( $P .016$; Table 2$)$ than maxillary teeth.

Table 1. Distribution by group of teeth

\begin{tabular}{|c|c|c|c|c|}
\hline Clinical features & $\begin{array}{l}\text { Balanced } \\
\text { Force }(\mathrm{BF}) \\
(\mathrm{n}=72)(\%)\end{array}$ & $\begin{array}{l}\text { Protaper Next } \\
(\mathrm{PTN})(\mathrm{n}=72)(\%) \\
(\%)\end{array}$ & $\begin{array}{l}\text { Reciproc } \\
(\mathrm{R})(\mathrm{n}=72)(\%)\end{array}$ & $\begin{array}{c}\text { Total } \\
(\mathrm{n}=216)\end{array}$ \\
\hline $\begin{array}{l}\text { Female } \\
\text { Male } \\
\text { Maxillary teeth } \\
\text { Incisorsand canines } \\
\text { Bicuspids } \\
\text { Molars } \\
\text { Mandibular teeth } \\
\text { Incisor and canines } \\
\text { Bicuspid } \\
\text { Molars }\end{array}$ & $\begin{array}{l}38(52.78) \\
34(47.22 \\
(44.91) \\
37(17.3) \\
2(2.78) \\
12(16.67) \\
23(31.94) \\
35(16.20) \\
3(4.17)\end{array}$ & $\begin{array}{l}40(55.56) \\
32(44.44) \\
37(17.3) \\
3(4.17)\end{array}$ & $\begin{array}{l}41(56.94) \\
31(43.06) \\
37(17.3) \\
2(2.78) \\
11(15.28) \\
24(33.33) \\
35(16.20) \\
1(1.39)\end{array}$ & $\begin{array}{l}119(55.09) \\
97 \\
111(51.39) \\
22(30.56) \\
18(25.00) \\
11(15.28) \\
105(48.60) \\
6(1.00)\end{array}$ \\
\hline
\end{tabular}




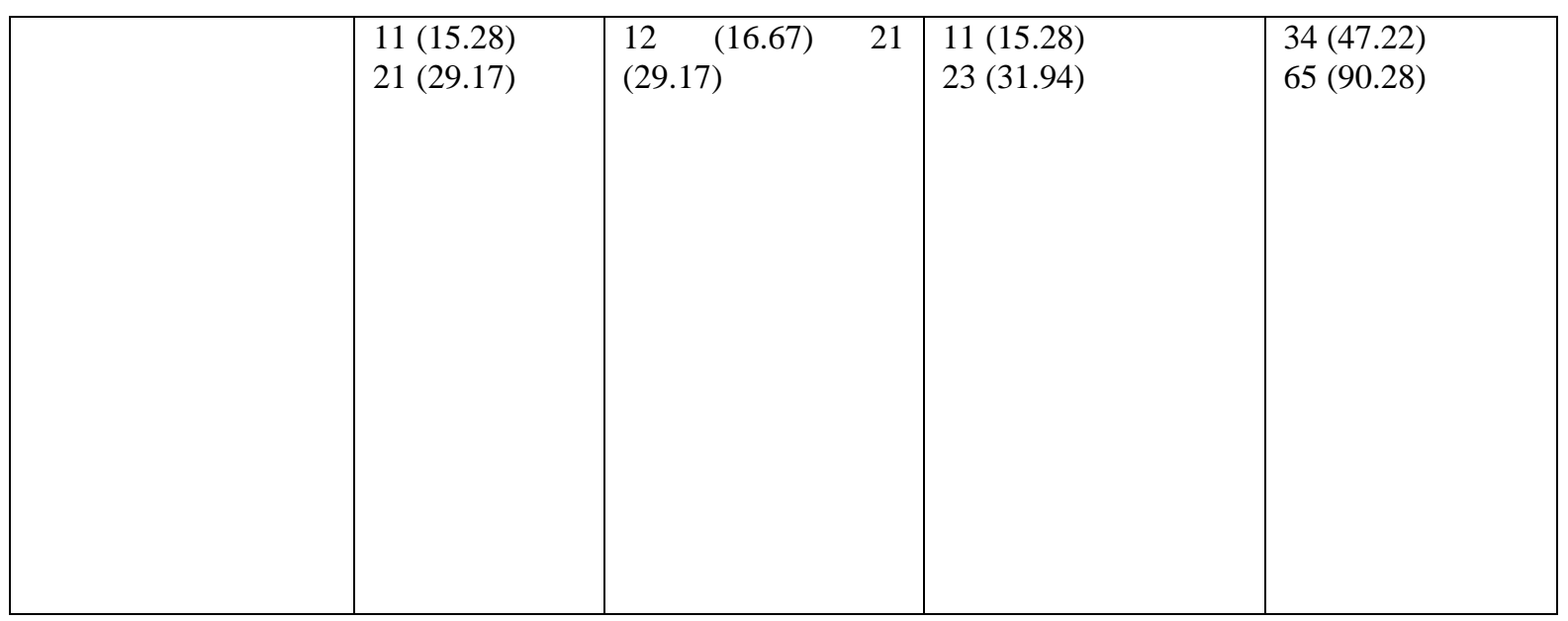

$p=0.05$

Table 2. Kruskal/Wallis test applied to the post-endodontic pain results for the groups Balanced Force, Pro Taper Next and Reciproc

Instrumentation

Technique

Pain after $24 \mathrm{~h}$

Balanced force

Pro Taper Next

Reciproc

Pain after $48 \mathrm{~h}$

Balanced force

Pro Taper Next

Reciproc

Pain after $72 \mathrm{~h}$

Balanced force

Pro Taper Next

Reciproc $\mathrm{n}$

Mean

.58

.65

$72 \quad .87$
.82

.81

.96

Standard deviation

.24

.43

.42

.2315

$\begin{array}{lll}72 & .23 & .42 \\ 72 & .21 & .59\end{array}$

$\mathrm{p}=0.05$

Table 4. Distribution of teeth by Randomization Factors

$\begin{array}{lcll} & \text { Balanced } & \text { Protaper } & \text { Reciproc } \\ 24 \text { hrs. after } & \text { Force }(\mathrm{BF}) & \text { Next (PTN) } & (\mathrm{R}) \\ & (\mathrm{n}=72)(\%) & (\mathrm{n}=72)(\%) & (\mathrm{n}=72)(\%) \\ \text { Quantity None } & 51(70.83) & 51(70.83) & 54(75) \\ \text { One tablet } & 12(16.66) & 13(18.05) & 11(15.27) \\ \text { Two tablets } & 9(12.5) & 7(9.72) & 7(9.72) \\ \text { Three tablets } & 0 & 1(1.38) & 0\end{array}$

$\mathrm{p}=0.05$

\section{Discussion}

Pain by itself is difficult to understand and measure specially when it happens suddenly in patients. The principal difficulties in learning aching and discomfort is the participant's idiosyncratic assessment and its 
dimension. For this purpose, planning the evaluation form has to be completely comprehended by participants.

In our research, a simple spoken classification was followed in the feed- back procedure with 3 classes: minor, modest, and acute. These classes were clearly comprehended by participants and were described by the occurrence or nonappearance of the necessity for pain-relieving treatment.

Pre-operative pain is one of the highest predictors of post-endodontic pain (20). Thus, only teeth with IP indicated for RCT because of prosthodontic purposes were chosen for this research. All treatments were performed in one-visit to avoid any the possible influence of intra canal medication or other issues generating pain and the involucrate teeth in the three groups were released of any early occlusal points after endodontic procedures so that unsuitable traumatic occlusion would not disturb the outcomes.

In this research, correct measure of WL during RCT was furthermore crucial. WL was estimated with an EAL and confirmed with a radiograph. Root ZX EAL was employed because its exactitude has been established in two clinical environments (21,22-24). As suggested by Herrera et al. (25), electronic WL measurement was repetitive after cervical and middle thirds shaping.

When clinicians combine radiographic interpretation and digital RC dimensions, occasionally outcomes do not match. In the occasion of inconsistency among both magnitudes, the electronic assessment would be chosen (26-28), as in this study.

In a recent study (29) was demonstrated that the dimension of the file employed to preserve AF open varied. We methodically used a \#10 width file to maintain AP in this study. Operating major widths to maintain AP can produce damage of surrounding tissues, hard control in complete RCT. All of these situations predispose the occurrence of post-endodontic pain.

It is well known that forcing of endodontic files outside the AF can send a diversity of toxic materials to the surrounding tissues, which can generate pain (30). Georgepoulou et al. showed a significantly major occurrence of pain if through the modeling procedure, instruments or material were involuntary placed outside the AF instead of maintaining them inside the canal (31). In our protocol, there is no over instrumentation, AP was maintained in all cases. Nevertheless, AP does not appear to be related to postendodontic pain in vital condition because of its control during RCT (32).

Furthermore, Torabinejad et al. (33) stated that inadvertent over-passage of instrument, it can occur while determining WL, doesn't interfere with the incidence of post-endodontic pain. Our methodology was similar to them, because likely we employed only thin files to establish the WL. This study supports our results in that apical over extension does not generate post-endodontic pain. Though, it varies from our research in that they didn't maintain AP during all the RCT.

Siqueira et al. (34) discovered little frequency of flare-ups following RCT in teeth with necrotic tissue or teeth with previous RCT if AP was maintained. They identified that maintenance of AP does not affect postendodontic pain. This was not measured in our research. In our report, we did not treat clinical cases for retreatment procedures and flare-ups were not evaluated.

In our research, we reduce the variation in the procedures following protocols based on recommendations by authors and manufacturers. Clean and shape procedures were performed on root thirds using brushing and reciprocating movements respectively followed a final irrigation with cold $\left(6^{\circ} \mathrm{C}\right) 17 \%$ EDTA gently delivered to the WL using a cold $\left(6^{\circ} \mathrm{C}\right)$ sterile metallic micro cannula attached to the Endovac supported in an early scientific report (35-39).

\section{Conclusion}

The incidence of post-endodontic pain is lower when Apical Patency is maintained and presence/absence of pre-operative pain has to be consider. When previous symptoms are present, occurrence and period of pain is longer in teeth with this condition that when AP is maintained.

We thank Prof. Dr. Michael Hülsmann for his valuable assistance in reviewing this manuscript.

The authors deny any conflicts of interest related to this study.

\section{References}

1. Ince B, Ercan E, Dalli M, et al. Incidence of postoperative pain after single- and multi-visit endodontic treatment in teeth with vital and non-vital pulp. Eur J Dent 2009; 3:273-9. 
2. Watkins CA, Logan HL, Kirchner HL. Anticipated and experienced pain associated with endodontic therapy. J Am Dent Assoc 2002; 133:45-54.

3. Torabinejad M, Kettering JD, McGraw JC, et al. Factors associated with endodontic interappointment emergencies of teeth with necrotic pulps. J Endod 1988;14: 261-6.

4. Souza RA. The importance of apical patency and cleaning of the apical foramen on root canal preparation. Braz Dent J 2006; 17:6-9.

5. Monsef M, Hamedzadeh K, Soluti A. Effect of apical patency on the apical seal of obturated canals. J Endod 1997; 23:253.

6. Monsef M, Hamedzadeh K, Soluti A. Effect of apical patency on the apical seal of obturated canals. J Endod 1998; 24:284.

7. Fava L. Acute apical periodontitis: incidence of post-operative pain using two different root canal dressings. Int Endod J 1998; 31:343-7.

8. Buchanan LS. Management of the curved root canal. J Calif Dent Assoc 1989; 17:18-27.

9. Izu KH, Thomas SJ, Zhang P, Izu AE, Michalek S. Effectiveness of sodium hypochlorite in preventing inoculation of periapical tissues with contaminated patency files. J Endod 2004; 30:92-4.

10. Roane JB, Sabala CL, Duncanson MG. The "Balanced Force" Concept for Instrumentation of Curved Canals J Endod 1985, 5(11): 203-211.

11. Flanders D. Endodontic patency: how to get it, how to keep it, why it is so important. N J State Dent J 2002; 68:30-2.

12. Ferraz CC, Gomes NV, Gomes BP, et al. Apical extrusion of debris and irrigants using two hands and three engine-driven instrumentation techniques. Int Endod J 2001;34: 354-8.

13. Bürklein S, Schëafer E. Apically extruded debris with reciprocating single-file and full-sequence rotary instrumentation systems. J Endod 2012; 38:850-2.

14. Yared G. Canal preparation using only one Ni-Ti rotary instrument: preliminary observations. Int Endod J 2008; 41:339-44.

15. Gutmann JL, Gao Y. Alteration in the inherent metallic and surface properties of nickel-titanium root canal instruments to enhance performance, durability and safety: a focused review. Int Endod J 2012; 45:113-28.

16. Reddy SA, Hicks ML. Apical extrusion of debris using two hands and two rotary instrumentation techniques. J Endod 1998; 24:180-3.

17. Al-Omari MAO, Dummer PMH. Canal blockage and debris extrusion with eight preparation techniques. J Endod 1995; 21:154-8.

18. Arias A, Azabal M, Hidalgo JJ, de la Macorra JC Relationship between post endodontic pain, tooth diagnostic factors, and apical patency. 2009; 2: 189-192.

19. Kirchhoff AL, Fariniuk LF, Mello I. Apical extrusion of debris in flat-oval root canals after using different instrumentation systems. J Endod 2015; 41:237-41.

20. Glennon JP, Ng YL, Setchell DJ, et al. Prevalence of and factors affecting post preparation pain in patients undergoing two-visit root canal treatment. Int Endod J 2004; 37:29-37.

21. Luiz F, Santana D, Correia L. The ability of two apex locators to locate the apical foramen: an in vitro study. J Endod 2006; 32:560-2.

22. Tselnik M, Baumgartner J, Gordon Marshall J. An evaluation of Root ZX and Elements diagnostic apex locators. J Endod 2006; 31:507-9.

23. Welk A, Baumgartner J, Gordon Marshall J. An in vivo comparison of two frequency- based electronic apex locators. J Endod 2003; 29:497-500.

24. Dunlap CA, Remeikis NA, BeGole EA, Rauschenberger CR. An in vivo evaluation of an electronic apex locator that uses the ratio method in vital and necrotic canals. J Endod 1998; 24:48-50.

25. Herrera MC, Abalos A, Planas J, Llamas R. Influence of apical constriction diameter on Root ZX apex locator precision. J Endod 2007; 33:995-8. 
26. Lucena-Martín C, Robles-Gijón V, Ferrer-Luque CM, Navajas-Rodriguez de Mondelo JM. In vitro evaluation of the accuracy of three electronic apex locators. J Endod 2004; 30:231-3.

27. Kim-Park MA, Baughan LW, Hatwell GR. Working length determination in palatal roots of maxillary molars. J Endod 2003; 29:58-61.

28. Williams CB, Joyce AP, Roberts S. A comparison between in vivo radiographic working length determination and measurement after extraction. J Endod 2006; 32:624-7.

29. Caillateau J, Mullaney T. Prevalence of teaching apical patency and various instrumentation and obturation techniques in United States dental schools. J Endod 1997; 23:394-6.

30. Nobuhara W, Carnes D, Gilles J. Anti-inflammatory effects of dexamethasone on periapical tissues following endodontic overinstrumentation. J Endod 1993; 19:501-7.

31. Georgepoulou M, Anastassiadis P, Sykaras S. Pain after chemo mechanical preparation. Int End J 1986; 19:309-14.

32. Fox J, Atkinson J, Dinin A, et al. Incidence of pain following one-visit endodontic treatment. Oral Surg 1970; 30:123-30.

33. Torabinejad M, Kettering J, McGraw J, Cummings R, Dwyer T, Tobias T. Factors associated with endodontic interappointment emergencies of teeth with necrotic pulps. J Endod 1988; 14:261-6.

34. Siqueira J, Rôças I, Favieri A, et al. Incidence of postoperative pain after intracanal procedures based on an antimicrobial strategy. J Endod 2002; 28:457-60.

35. Modabber A, Rana M, Ghassemi A, et al. Three-dimensional evaluation of postoperative swelling in treatment of zygomatic bone fractures using two different cooling therapy methods: a randomized, observer-blind, prospective study. Trials 2013; 14:1-10.

36. Bleakley CM, McDonough SM, MacAuley DC, Bjordal J. Cryotherapy for acute ankle sprains: a randomized controlled study of two different icing protocols. Br J Sports Med 2006; 40:700-5.

37. Al-Nahlawi T, Abo Hatab T, Abd Alrazak M, et al. Effect of intracanal cryotherapy and negative irrigation technique on post endodontic pain. J Contemp Dent Pract 2016; 17:990-6.

38. Vera RJ, Ochoa J, Romero M, Vazquez-Carcaño M, Ramos-Gregorio CO, Rosas R, Cruz A, Sleiman P, Arias A. Intracanal Cryotherapy Reduces Postoperative Pain in Teeth with Symptomatic Apical Periodontitis: A Randomized Multicenter Clinical Trial. J Endod. 2018; 1: 4-8.

39. Keskin C, Özdemir Ö, Uzun İ, Güler B. Effect of intracanal cryotherapy on pain after single-visit root canal treatment. Aust Endod J. 2017; 43:83-88. 